\title{
Dossier Presentation
}

\section{The Second Person}

The clash between the first-person and the third-person perspectives is wellknown to anyone familiar with the literature in the philosophy of mind. We have a privileged access to our own mental states, acts, or events; there is clearly an asymmetry between the way we know our own mental states and the way we know the mental states of other persons through mindreading or empathy. Thus, the first-person perspective is subjective. 1] From that perspective we think of ourselves as conscious and rational beings, with responsibilities, commitments, and values. This is the obliged starting point of everybody. The knowledge we have about ourselves from that perspective is not scientific and does not require any special training.

The third-person perspective is the one of natural sciences. It is objective. From that perspective, we are organisms caught in the causal network of the world, like any other object around us. When natural sciences look at the human body, what is seen is shown by anatomical boards. We have a thirdperson perspective when different people can look at the same objects, consider and weight the same evidence, share the same methods, reach the same conclusions. The third-person perspective presupposes the possibility to engage in the same sort of activity (investigating, theorizing) and to agree with other people, thus, to access, somehow, and assess, other people's beliefs. Without that (imperfect) access to other's beliefs, there wouldn't be objectivity. But this is what we call intersubjectivity. So, objectivity is grounded in intersubjectivity. But intersubjectivity is based on the capacity to put oneself in someone else's skin. This is a first-person ability, that of representing other people's mental states, a metarepresentational capacity grounded in the first-person perspective.

It is now easy to see why the idea of introducing a second-person perspective became conceptually so urgent. The second-person perspective is intersubjective, rooted in the first-person

\footnotetext{
${ }^{1}$ For a similar characterization of the three perspectives, see Michael Pauen (2012): "The Second-Person Perspective", Inquiry: An Interdisciplinary Journal of Philosophy, 55:1, 33-49.
} 
perspective, and grounding the thirdperson perspective of science. The second-person perspective is necessary to complete the picture, to close the gap and to explain genetically how we can get outside the close circle of subjectivity by sharing beliefs and methods. This is how we reach collectively "a view from nowhere."2]

There are many different angles to approach the concept SECOND PER$\mathrm{SON}$. The second-person perspective appears as indispensable for deepening the understanding of ourselves as agents provided with abilities to communicate and use mentalistic terms. A long time ago, in Port-Royal, the great Arnauld saw clearly that our minds are not completely opaque; we can "penetrate imperfectly" each other's minds, and this is what we do in any verbal interaction. We speak the way we do because we have that "imperfect penetration" of each other's minds: "We cannot reflect, however little, on the nature of human language, without recognizing that it is entirely founded on this imperfect penetration of the mind of the others. This is why, in talking, there are so many things we do not express." $3^{3}$ Today, we call that capacity "mindreading". According to developmental psychologists, it starts developing very soon, at about 18 months, and is completed around 48 months, when children pass the false belief test. ${ }^{4}$ One century after Port-Royal, Thomas Reid introduced the idea of social operations of the mind 5

How do we learn to apply mental concepts at all? Ostensive teaching does not work for mental concepts. How do we come to use "I feel a pain"? And then "you are in pain"? Decades ago, Peter F. Strawson raised an interesting hypothesis: "that it is a necessary condition of one's ascribing states of consciousness, experiences, to oneself, in the way one does, that one should also ascribe them, or be prepared to ascribe

\footnotetext{
${ }^{2}$ Thomas Nagel, in A View from Nowhere (1986) saw the problem acutely: "This book is about a single problem: how to combine the perspective of a particular person inside the world with an objective view of the same world, the person and his viewpoint included. It is a problem that faces every creature with the impulse and the capacity to transcend its particular point of view and to conceive of the world as a whole." p. 3.

${ }^{3}$ Arnauld A. Nicole P. (1669-1672). La grande Perpétuité de la foi de l'Église Catholique sur l'Eucharistie, ed. by l'Abbé M**, Paris, Imprimerie de Migne, chez l'éditeur rue d'Ambroise, Hors la barrière d'Enfer, 1841, Vol. 2, Book I, p. 81; translation by A.L).

${ }^{4}$ See Alvin Goldman, Simulating Minds. The Philosophy, Psychology and Neuroscience of Mind Reading. Oxford: O.U.P., 2006, as a main source of information on the subject.

${ }^{5}$ Thomas Reid, Essays on the Active Powers of Man [1785], in The Works of Thomas Reid, Vol. 1, facsimile of the 1872 edition. Elibron Classics, 2005. "By ['social operations'] I understand such operations as necessarily suppose intercourse with some other intelligent being. A man may understand and will; he may apprehend and judge and reason, though he should know of no intelligent being in the universe besides himself. But, when he asks information or receives it; when he bears testimony or receives the testimony of another; when he asks a favour, or accepts one; when he gives a command to his servant or receives one from a superior; when he plights his faith in a promise or contract - these are acts of social intercourse between intelligent beings, and can have no place in solitude. They suppose understanding and will; but they suppose something more, which is neither understanding nor will; that is society with other intelligent beings." P. 244. "All languages are fitted to express the social as well as the solitary operations of the mind. Indeed, it may indeed be affirmed, that, to express the former, is the primary and direct intention of language. A man who had no intercourse with any other intelligent beings, would never think of language. p. 245.

${ }^{6}$ Peter F. Strawson, Individuals. An Essay in Descriptive Metaphysics. London: Routledge, 1959, p. 99.
} 
them, to others who are not oneself." 6 We learn to apply mental concepts to ourselves when we are able to apply them to other people. A human being becomes a person with a first-person perspective in the full sense of the word when she has at her disposal a bunch of concepts through which she can think of herself as distinct of any other thing or person.7 Therefore, having a firstperson perspective is a property one cannot have in isolation. We have learned from Externalism that the instantiation of such a relational property presupposes the existence of someone else.

In a paper titled "The Second Person," Donald Davidson exposes once more his idea of triangulation: a learner (usually a child), a teacher, who can be anyone (a family member, a neighbor, etc.), and a common background. Triangulation is a way to explain how we acquire our basic concepts, the meanings of words, and our propositional attitudes. Here is the idea: “...if I am right, the kind of triangulation I have described, while not sufficient to establish that a creature has a concept of a particular object or kind of object, is necessary if there is to be any answer at all to the question of what its concepts are concepts of."18"... without a second creature responding to the first, there can be no answer to the question." (Ibid.). Triangulation establishes the public character of language: "if anyone is to speak a language, there must be another creature interacting with the speaker." (Ibid.) Davidson goes further and defends the social character of thought: "Belief, intention, and the other propositional attitudes are all social in that they are states a creature cannot be in without having the concept of intersubjective truth, and this is a concept one cannot have without sharing, and knowing that one shares, a world and a way of thinking about the world with someone else."' 9

The theme of the second person has received very high attention in recent years, so much so as we can speak of a "You Turn" in philosophy of cognition and psychology. ${ }^{10}$

The introduction of the secondperson issue in analytical moral philosophy is mainly due to another of Strawson's classic papers, Freedom and Resentment (1962) 11 in which he drew a famous distinction between participant and objective standpoint. The lat-

\footnotetext{
${ }^{7}$ See Lynne Rudder Baker, Person and Bodies. A Constitutive view. Cambridge: C.U.P., 2000: "the first-person perspective is relational in that it would be impossible for a being truly alone in the universe to have a first-person perspective." Pp. 69-70.

${ }^{8}$ Donald Davidson, "The Second Person", Midwest Studies in Philosophy, XVII (1992), p. 263.

${ }^{9}$ Ibidem, p. 265.

${ }^{10}$ Naomi Eilan, "You Turn", Philosophical Exploration, 2014, pp. 1-14, republished in N. Eilan (ed.), The Second Person: Philosophical and Psychological Perspectives, London, Routledge, 2017.

${ }^{11}$ Peter F. Strawson, "Freedom and Resentment," Proceedings of the British Academy, 48, 1962, pp. 1-25, republished in Freedom and Resentment and Other Essays, London, Methuen, 1974.
} 
ter refers to people and things in the deterministic natural world, i.e. from an objective point of view, whereas the former, on the contrary, presupposes other people and their responsibility, introducing into the ethical debate the notion of "reactive attitudes" like gratitude, indignation, shame, anger, resentment, sympathy, guilt, and moral blame, which involve, for their activation, the presence of another person or other people. Even though Strawson does not talk explicitly about a secondperson standpoint, his paper is considered today a pioneering contribution to the debate on this topic.

More recently, the concept of second person has been discussed in moral philosophy by Yale philosopher Stephen Darwall, in a book that has quickly become a classic defining the conceptual frame of discussion in ethics: The Second-Person Standpoint. Morality, Respect, and Accountability (2006).12 According to Darwall, the second-person condition is a condition in which a rational agent becomes self-aware as a moral agent when interacts with other people. This type of condition, or standpoint, arises within a community in which people interact with each other. Furthermore, the community has accepted that people have the authority to make demands and claim rights within these interactions. A simple group of individuals, consequently, becomes a moral community. Moreover, according to Darwall, morality cannot be based on a purely rational agent, as in the classical Kantian tradition, a principle defended for example by Korsgaard, but if we want to articulate and justify the principles of morality, we must take into account the point of view of a second person involved in the action. Thus, Darwall argues, the moral concepts of obligation, dignity and respect should be justified from the point of view of another rational being. Moral solipsism, in the perspective that Darwall is defending, is not only avoided but impossible because dialogue becomes the mark of rational agent's moral thinking.

Darwall's reformed Kantianism is similar to that of Martin Buber's dialogical principle, ${ }^{14}$ and to some extent his second-person approach in moral philosophy can be compared with some authors within the phenomenological tradition.

The second person is a main concern in the phenomenological tradition, and it has taken different forms in literature: one also speaks of collective intentionality or phenomenological inter-

\footnotetext{
${ }^{12}$ Stephen Darwall, The Second-Person Standpoint: Morality, Respect, and Accountability, Cambridge MA, Harvard University Press, 2006.

${ }^{13}$ See the Symposium on Darwall's book by Christine M. Korsgaard, "Autonomy and the Second Person Within: A Commentary on Stephen Darwall's The Second Person Standpoint," Vol. 118, No. 1, October 2007, pp. 8-23.

${ }^{14}$ Martin Buber, 1923, Ich und Du, Leipzig, Insel Verlag, 1937, I and Thou, transl. by R. G. Smith, New York, Scribner, 2000.
} 
subjectivity.

The first research in the secondperson phenomenology can be traced back to the question discussed by Husserl in the Fifth Cartesian Meditation about the non-solipsistic nature of subjectivity as well as in the manuscripts published in vol. XIII-XV of Husserliana about the possibility for the transcendental ego to constitute itself in relation to others, where Husserl claims that transcendental subjectivity exists in consort with others. As Shaun Gallagher observes: "in Husserl's Fifth Meditation, he develops a transcendental analysis of how we experience the other person. The analysis claims a universal validity insofar as it is proposed as an eidetic insight into the structure of any possible experience of others."15

For Husserl, intersubjectivity is essentially an empathic experience. After Husserl, many phenomenologists have developed an analysis on empathy, as Edith Stein, Max Scheler, and Alfred Schutz, according to whom empathic intuition seems to be the only access to the other's experience. But is empathy really possible? Feeling in a way analogous to my own can be interpreted as just a case of emotional mindreading. The concrete possibility of empathy is based, ultimately, on an argument by analogy. Against the pos- sibility of a phenomenological account of empathy some philosophers have argued the only mind to which I can have access is my own mind. The access I have to the thoughts and internal states of other people is always mediated by their bodily behavior. And, if we assume that it is impossible from a simple observation of another person's body and actions to give us information about his or her thoughts, we must conclude that it is not possible to have access to another person's thoughts and feelings by empathic insight. Empathy by analogy is impossible. Thus, any second-person phenomenology is false. According to the analogy argument, all I can do is to observe my own actions and behaviors as a result of an external cause and, then, to infer that the analogous behavior of other bodies refers to experiences, states, and thoughts similar to my own. This kind of analysis remains, however, a first-person phenomenology. The Husserlian Cartesianism, it is said, assumes in the final analysis a constitutive asymmetry between first-person and second-person experience: I cannot perceive the other in the certain and self-evident way in which I can perceive myself, my thoughts and my feelings.

The phenomenological approach as an inherently solipsistic one has been

\footnotetext{
${ }^{15}$ Shaun Gallagher, Phenomenology, New York, Palgrave Macmillan, 2012, p.182

${ }^{16}$ D. C. Dennett, The intentional stance, Cambridge, MA, MIT Press, 1987, p.154, 209-210. See also D. C. Dennett, "The fantasy of first-person science," in S. Wuppuluri and F. Doria (eds.), The Map and the Territory: Exploring the Foundations of Science, Thought and Reality, Cham, Springer, 2001/2018, pp. 455-473.
} 
radically criticized by Dennett in what he calls "methodological solipsism." 16 All the insights from which phenomenology starts to offer an understanding of the human mind are private. As such, they fail to explain cognition from the second-person point of view and from the first-person plural standpoint (i.e. the we-standpoint) as well. Solipsism remains the main argument against the possibility of both a phenomenology of the I-Thou relation and a phenomenology of social cognition.

In fact, this argument was already criticized by Scheler, because it presupposes what it intends to explain. ${ }^{17}$ The premise of this argument is that we already attribute to others such a thing as a mind, while the only thing we are not convinced of is how to interpret actions and behaviors of this other mind. However, phenomenology refuses to recognize the implicit idea in the argument that the mind is something like a hidden object within a visible but silent and mysterious body. There is no such a thing as a mind into a body. Early phenomenologists, like Scheler, held, instead, that in second-person experience what is experienced is not a mind but rather the other in its indivisible unity of mind and body. It is only by further abstraction that we are able to divide other's behavior into an 'inner' and an 'outer', i.e., on the one hand thoughts and on the other hand actions.

In this sense, the first phenomenologist to revise the Husserlian intersubjectivity for avoiding solipsism, in addition to Scheler, was Heidegger through his concept of being-with (Mit-sein) as a constitutive concept of human experience. Furthermore, other philosophers of the phenomenological tradition have criticized the first-person methodological solipsism and developed a secondperson phenomenology, particularly in the French phenomenological tradition: Sartre and his analysis of shame in L'Etre et le Néant, Levinas and his concept of face of the other (visage d'autrui), Merleau-Ponty and his core notion of intercorporeality, Derrida and the question of language. At the root of any phenomenological theory, we find the act of direct perception of the other as a mind-body unity. In this respect, the notion of embodiment in MerleauPonty's account of cognition and perception offers a brilliant and challenging theoretical model and still plays a crucial role in current philosophy of mind 18

In accordance with this tradition, a phenomenologist assumes this directexperience point of view without mentalizing other people. What philosophical analysis should do is recognize that the body of another person as well as its presence in our life are not sim-

\footnotetext{
${ }^{17}$ Max Scheler, Wesen und Formen der Sympathie (1923), The Nature of Sympathy, London, Routledge Kegan Press, 1954, p.315

${ }^{18}$ See, for example, Shaun Gallagher, How the Body Shapes the Mind, Oxford, Oxford University Press, 2005.
} 
ply something we relate to by causal impact. We are related to other people in a context endowed with meaning. In this sense, empathy is not only a mere personal feeling or "mindreading", but it presents an intentional structure. In this case, lived experiences of another person and what they mean within a determined context are the objects toward which intentional acts are directed.

Recently, a phenomenological scholar who has contributed the most to the second-person analysis improving this tradition is undoubtedly the Danish philosopher Dan Zahavi. He has developed in his work a phenomenology of "you-experience" and has also enlarged phenomenological analysis to social cognition and collective intentionality. ${ }^{19}$

Despite the possibility of a current phenomenological approach in cognitive science, the interplay between these two traditions remains still arduous. The fundamental difference between the analytic and the phenomenological tradition with respect to the role of the second person in cognition and action consists, in the end, in the way in which the question raised. In the analytic context the problem is more about the conditions of our own cognition, i.e., it is about whether or not we can say to know others exac- tly as we know a stone or a tree. The philosophical inquiry is essentially inferential and raises doubts about the epistemic conditions, i.e., conditions of justification of our beliefs about other minds' mental states. Yet, if our problem is to explain how emotions and thoughts of another mind can be inferred, we will be forced to assume that these experiences are intrinsically hidden and obscure. The suspect is this way of thinking could be a myth - what Jacques Bouveresse called "the myth of interiority." 20 Why should we assume that other minds and their thoughts are more mysterious than our own? Quite the opposite, in the phenomenological tradition, the core problem is about the act of perceiving another person for what her actions mean. The phenomenological model asks us to perceive the experience of another person insofar as it is manifested in her actions, in her words and attitudes, and to take into account a certain situation in which we too are involved. Finally, if my question is to justify how I can know with certainty whether another person is angry, probably the inferential model does not help me to answer. But if I Wittgensteinianly say "Don't think, look at her face!" I can neutralize skepticism about second-person phenomenology using the perceptual model of this tradition.

\footnotetext{
${ }^{19}$ Dahn Zahavi, Self and Other: Exploring Subjectivity, Empathy, and Shame, Oxford, Oxford University Press, 2014.

${ }^{20}$ Jacques Bouveresse, Le Mythe de l'intériorité. Expérience, signification et langage privé chez Wittgenstein, Paris, Editions de Minuit, 1976
} 
This could be a viable way in a short introduction to the second-person stance to put in dialogue two traditions that sometime are difficult to compare.
This issue opens with a paper by $\mathrm{Si}^{-}$ mone Gozzano (University of L'Aquila, Italy) on bodily pain and the second person account. The location of bodily pain traditionally represents a privileged case of first-person standpoint. However, using the Davidsonian concept of "triangulation," Gozzano interestingly argues that "it is in the interplay between the first and second person" where we can find a solution to the puzzle of bodily pain. The first part of the contribution explores the difference between two major theories about pain localization: representationalism and experientialism. In the first case, pain is a perception of something localized in the body, in other words, it is a representational body part. Even if the representational content could have a phenomenal character, a representationalist can always argue that "different locations entail different experiences," so that the content of experience is always linked to physical conditions. But how can we explain pain localization in the case of phantom limb? Representational model seems to give us a wrong account in this case. According to the second theory, pain is a modification of the subject. When we say,
"John feels pain in his toe," we are in fact saying "John is feeling his toe painfully." Experiential contents are not representational but adverbial, they connect mind with a state of the subject and describe a modification of subjective experience, no matter what happens to the body. In the second part of his contribution, Gozzano introduces Davidson's concept of triangulation, a process of interaction between the first and the second person, in order to reappraise representationalism. Finally, in the third part, the representational model is reformed. Gozzano proposes to account for the representational map model as an error of our cognition and he argues that such as failure is due to the limits of our representational system rather than of the conceptual basis of representationalism itself.

Antoni Gomila's (University of Balearic Islands, Spain) paper focuses on self-knowledge as a practical knowledge. Gomila explores the possibility to acquire self-knowledge understanding other people, in this case, according to Gomila, the second-person point of view would be a condition for conceptualizing our own proprioceptive experience. Moreover, Gomila ar- 
gues, self-knowledge would not have the mark of transparency and authority because it is "revisable as any other form of knowledge." And, he adds, we should recognize this form of knowledge not in an epistemic way, rather self-knowledge should be perceived as wisdom. Strawsonian "reactive attitudes," according to Gomila, are dispositional states which drive our actions as agents shaping what the author calls the "interpersonal self." Whereas epistemic states are momentary episodic events, our identity as responsible rational agents is a more stable state. This reflexive attitude, activated in contrast to other people, i.e. in relation to a second-person experience, drives our life and constitutes our self-knowledge as a practical achievement.

The next contribution turns on the connection between epistemic concerns about the conditions for agent's moral responsibility and second-person standpoint. Beatriz Sorrentino Marques (Federal University of Mato Grosso) examines the issue if a moral agent must know what she does and whether she needs to know the moral meaning of her actions in order to be responsible. The paper helpfully discerns between epistemic concern which constitutes a condition for moral action and epistemic concerns that are not involved with other conditions in the action. The main problem is to understand if a such external epistemic condition is necessary for being a responsi- ble agent. In her paper, Sorrentino defends arguments for the independence of moral action from external epistemic conditions. The paper introduces in the first part the second-person perspective, in the second part Sorrentino analyses Strawson's and FisherRavizza's arguments for the independency of moral action and, finally in the third part, the contribution takes in-depth look at Darwall's and Strawson's conclusions according to which to be aware of moral meaning of an action is not a necessary condition for responsibility.

Roberto Horacio da Sá Pereira's (Federal University of Rio de Janeiro) contribution develops the so-called "Interaction Theory" or "the second-person approach," as an alternative model for the direct cognition of third-person states. Starting from a critical reformulation of the classic perceptual model proposed by Dretske, Pereira proposes a different model for an introspective cognition of one's own mental states. Against Dretske, in the first part, Pereira maintains knowledge of basic emotions does not depend on "connective beliefs," and, further, holds no meta-representation is involved in this process, but rather, according to Pereira, just elementary concepts about emotions of others are entailed: contentment and displeasure. In the positive part of his paper, Pereira proposes that the direct perception of such elementary mental states is not, strictly 
speaking, a perception, but we should intend this mental act as a "perception of facts." But, what does that mean? Pereira answers that this kind of perception can be explained as an epistemological process that is both automatic and reliable. It does not involve any inference, reflection, theorization, or epistemic justification: e.g., the baby's perception of facial expression of her mother's displeasure does not constitute any reason in favor of the "belief" that the mother is displeased. According to Pereira, the notion of "belief" is not to be understood in the usual sense, rather it should be intended in the sense of a natural inclination for truth. Pereira justifies, in the final part of his paper, this kind of inclination as a result, or output, of an entirely subliminal process of a computational nature.

The last two papers in this volume focus on the second-person standpoint from a broader perspective. In the first one, Mariana C. Broens and Maria Eunice Q. Gonzales (São Paulo State University) examine the concept of "alterity" as a second-person standpoint. The paper considers other people involved in our interaction and the relevance of this interchange for philosophy of information and technology, anthropology, and history. Starting from typology of alterity proposed by Todorov, the paper explores three axes involving relations with other people: 1) the ethical and economic values that guide this interaction; 2) how people effectively interact with each other in the pragmatics of everyday life, and 3) the epistemic stance adopted toward another person. Inspired by Todorov in his attempt to understand deep aspects of intercultural relations in the period of Spanish colonization of Central America, the paper explores his typology of the second-person perspective for, finally, analyzing and focusing on the second axis. Broens and Gonzales argue that, in the same extent differences between Spanish and pre-colonial technologies were determinant in their impact and interactions, so technological innovations that currently permeate interpersonal relations are generating significant social changes in our everyday life. The paper concludes that, although it is difficult to anticipate the consequences of these social changes we too are living as a computerized society, visible signs of a such influence are already present in generative processes of our personal and collective (inter) identity.

In closing out the issue, Diana I. Pérez's (University of Buenos Aires) paper provides an interesting analysis about the second-person theme from a philosophy of art point of view. In her contribution, Pérez argues that the mental attribution from the second-person perspective can contribute to illuminate our understanding and engagement in art. Pérez provides to reconceptualize how human minds and their interaction with other human beings are complex phenomena interfaced with our aesthe- 
tic experience. In her paper, Pérez uses a very broad concept of "art," including not only the canonical concept of art-work typical of the Western culture but also many other artistic manifestations and activities such as cave paintings, children's doodles, tribal songs sing around a campfire, comics, manga, and children's stories. Our involvement with these various forms of musical, plastic, fictional art-works, is ubiquitous in our lives, and they shape, she argues, our human identity.

André Leclerc

(UnB/CNPq)

Federico Boccaccini

(UnB/Université de Liège) 
